\title{
lol: new language and spelling in instant messaging
}

\author{
Connie K. Varnhagen · G. Peggy McFall · Nicole Pugh • \\ Lisa Routledge $\cdot$ Heather Sumida-MacDonald • \\ Trudy E. Kwong
}

Published online: 2 May 2009

(C) Springer Science+Business Media B.V. 2009

\begin{abstract}
Written communication in instant messaging, text messaging, chat, and other forms of electronic communication appears to have generated a "new language" of abbreviations, acronyms, word combinations, and punctuation. In this naturalistic study, adolescents collected their instant messaging conversations for a 1 -week period and then completed a spelling test delivered over instant messaging. We used the conversations to develop a taxonomy of new language use in instant messaging. Short-cuts, including abbreviations, acronyms, and unique spellings were most prevalent in the instant message conversation, followed by pragmatic signals, such use of emoticons, emotion words, and punctuation, and typographical and spelling errors were relatively uncommon. With rare exceptions, notably true spelling errors, spelling ability was not related to use of new language in instant messaging. The taxonomy provides an important tool for investigating new language use and the results provide partial evidence that new language does not have a harmful effect on conventional written language.
\end{abstract}

Keywords Spelling · Instant messaging

C. K. Varnhagen $(\bowtie) \cdot$ G. P. McFall · L. Routledge $\cdot$ H. Sumida-MacDonald Department of Psychology, University of Alberta, Edmonton, AB T6G 2E9, Canada e-mail: varn@ualberta.ca

N. Pugh

Department of Psychology, University of Regina, Regina, SK, Canada

T. E. Kwong

Department of Psychology, MacEwan College, Edmonton, AB, Canada 


\section{Introduction}

Electronic technologies offer many different opportunities for written communication. Increasing numbers of people are communicating with each other through various technologies such as phone-based text messaging, Internet-based instant messaging, synchronous chat, asynchronous discussion forums, and e-mail. Many of these communications are interactive, much like a conversation but conducted at a distance (often both in time and space) and in written form. Possibly to speed up the communicative exchange (Werry, 1996), communicators have developed short cuts for expressing words, phrases, and emotions as well as textual and graphical pragmatic devices. These short cuts and pragmatic devices have become so ubiquitous in electronic communication that they are now being collected in dictionaries (e.g., Jansen, 2003; Shoeman \& Shoeman, 2007; http://www.netlingo.com; http://www. urbandictionary.com).

Electronic communication is very popular among adolescents; according to ongoing surveys from the Pew Internet and Family Life project, the vast majority of adolescents in the United States engage in various forms of electronic communication on a daily basis, and instant messaging is one of the most popular forms of electronic communication for this age group (Lenhart, Madden, \& Hitlin, 2005; Lenhart, Madden, Macgill, \& Smith, 2007; Lenhart, Rainie, \& Lewis, 2001). Instant messaging is a synchronous form of communication between two or more people, (a) using a specialized Internet application, such as AOL Instant Messenger (AIM), Windows Live Messenger (MSN), or ICQ, (b) within an online game or virtual world, such as the World of Warcraft Instant Messenger and Second Life chat, or (c) through a social networking site, such as Facebook or MySpace Instant Messaging.

As shown in Fig. 1, these instant messaging applications typically open a small window for communication. Each participant in the communication is identified by his or her user name and messages are displayed in the order in which they are posted. The format of these typed messages graphically represents turn taking in a conversation (Grinter, Palen, \& Eldridge, 2006; Merchant, 2001).

Typing is much slower and more error prone than is speaking (Herring, 1999, 2003); possibly to compensate for these issues, people communicating though instant messaging have developed short cuts to typing full words, such as $l 8 r$ for later, or acronyms for common phrases, such as brb for be right back (Werry, 1996). Although emotion is often assumed in online messages (Kruger, Epley, Parker, \& Ng, 2005), users may have developed text and graphic pragmatic devices to support or enhance communication functions (Lewis \& Fabos, 2005). These text and pragmatic devices include text or graphic "smileys" or emoticons to convey an expressive function of language, or abbreviations such as $Y W$ for you're welcome to express a phatic function (Jakobson, 1960).

While the media and some researchers, teachers, and parents (e.g., http://www. oxfordlearning.com/letstalk/texting-vs-writing-the-problem-with-instant-messag/; Lee, 2002) may interpret the technically incorrect language and spelling "errors" in instant messaging conversations as detrimental and incorrect, some researchers (e.g., Lewis \& Fabos, 2005; Merchant, 2001; Spatafora, 2008; Tagliamonte \& Denis, 2006) suggested that this phenomenon simply represents contemporary 


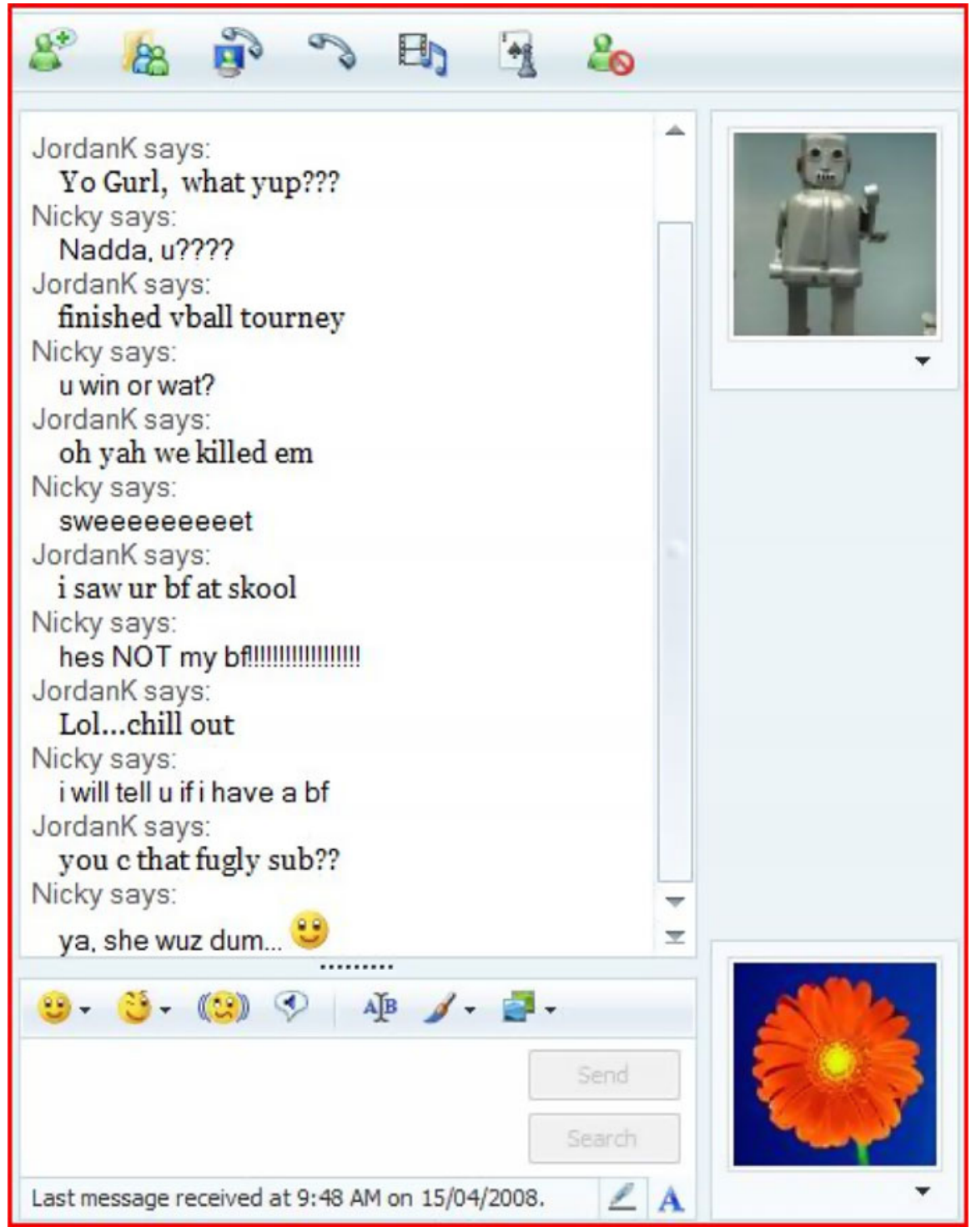

Fig. 1 Screen shot of Windows Live Messenger program with open conversation window

slang, a process in the evolution of the English language. Others (e.g., Crystal, 2006; Davis \& Brewer, 1997) go further to suggest the new linguistic structures developed for online communication may represent the creation of a "new media language," distinct from but complementary to conventional written English. As well, this new language may benefit students in terms of encouraging creativity in written expression and increasing literacy (Sternberg, Kaplan, \& Borck, 2007).

The present study focused on two goals: our first goal was to explore the nature of words produced in instant messages and their function within the conversation. 
Our second goal was to examine the relationships between spelling ability and new language use.

Developing a taxonomy of "new language" use in instant messaging is important for understanding this different communication medium, observing its evolution over time, and comparing instant messaging with other forms of computer-mediated communication. To examine our first goal of investigating the use of new language in online conversations, we selected adolescents as participants because this age group has grown up with the Internet and is the major user group of instant messaging (Lenhart et al., 2007; Lenhart et al., 2005; Lenhart et al., 2001). Adolescent participants collected a history of their instant messaging for a week. We then administered a standardized spelling test over the same instant messaging program to measure spelling ability, providing an ecologically valid measure of online spelling in that the participants typed their spelling in response to digitally recorded words.

We organized use of new language in instant messages into categories representing short cuts and pragmatic devices and counted apparent typographical errors and misspellings as shown in Table 1. We began with more general taxonomies developed by Werry (1996), Driscoll (2002), and Stevenson \& Shortis, (n.d.) to characterize new language use by adults in chat, another type of synchronous computer-based communication that serves different functions than instant messaging in the communicative process (Crystal, 2006; Kang \& Yang, 2006). These taxonomies included identifying abbreviations, acronyms, letter or number word substitutions, and emoticons; our taxonomy, as shown in Table 1, includes these categories as well as additional categories to more completely categorize new language use in adolescents' instant messaging. As well, we further examined the linguistic context in which the new language terms and characters were used to better understand the function of the different categories.

Given that girls report greater use of instant messaging than boys (Lenhart et al., 2005), we hypothesized that girls would use more new language and different types of new language than would boys. Similarly, given that older children report greater use of instant messaging than younger children (Lenhart et al., 2005; Spears, Seydegart, \& Zulinov, 2005), we hypothesized that new language use would increase with age.

To address our second goal of relating spelling ability with use of new language, we examined correlations between spelling ability and overall new language use as well as different types of new language use. If the new language of instant messaging is truly a new or a complementary language (e.g., Crystal, 2006; Lewis \& Fabos, 2005), then we might expect both positive and negative transfer between the two "languages" (Figueredo, 2006; Sparks, Patton, Ganschow, Humbach, \& Javorsky, 2008) based on interdependencies between the two languages (Cummins, 1979). Good spellers in conventional English might make greater use of new language compared with poorer spellers. On the other hand, in line with parental and media concerns (e.g., Lee, 2002), we might expect those who use more new language to be poorer spellers.

We recruited adolescents who used instant messaging on a regular basis to participate. The participants saved their instant messages for a 1-week period and then we randomly choose a 100 word sample from each adolescent to include in our corpus. We also administered a standardized spelling test to the participants over 
Table 1 New language categories and examples of new language

\begin{tabular}{|c|c|c|}
\hline Category & Example & Example in context \\
\hline \multicolumn{3}{|l|}{ Short cuts } \\
\hline Insider word & $\begin{array}{l}\text { hottie } \\
\text { fugly }\end{array}$ & $\begin{array}{l}\text { MAKE OUT WITH THAT HOTTIE } \\
\text { is that like a fugly slut? }\end{array}$ \\
\hline Abbreviation & $\begin{array}{l}\text { feelin } \\
\text { prolly }\end{array}$ & $\begin{array}{l}\text { how } \mathrm{r} \text { u feelin? } \\
\text { you could prolly look them up on the net }\end{array}$ \\
\hline Word combination & $\begin{array}{l}\text { wanna } \\
\text { gonna }\end{array}$ & $\begin{array}{l}\text { i wanna sign up for the yhl } \\
\text { i am gonna be gone sat and sunday }\end{array}$ \\
\hline Acronym & $\begin{array}{l}\text { bf } \\
\text { omg }\end{array}$ & $\begin{array}{l}\text { SHE HAS A BF } \\
\text { omg that is terrible }\end{array}$ \\
\hline Alphabet/letter & $\begin{array}{l}\mathrm{u} \\
2 \text { day }\end{array}$ & $\begin{array}{l}\text { what do u wanna talk about? } \\
\text { did u go to skool } 2 \text { day? }\end{array}$ \\
\hline Phonetic & $\begin{array}{l}\text { yer } \\
\text { wat }\end{array}$ & $\begin{array}{l}\text { you get yer stuff done tonight? } \\
\text { wat u doin? }\end{array}$ \\
\hline Lower case & $\begin{array}{l}\mathrm{i} \\
\text { elyssa }\end{array}$ & $\begin{array}{l}\text { i almost cried } \\
\text { r u talking to elyssa????? }\end{array}$ \\
\hline Contraction & $\begin{array}{l}\mathrm{im} \\
\text { thats }\end{array}$ & $\begin{array}{l}\text { im so excited } \\
\text { thats not cool }\end{array}$ \\
\hline \multicolumn{3}{|l|}{ Pragmatic devices } \\
\hline Emotion word & $\begin{array}{l}\text { hahahaha } \\
\text { soooooo }\end{array}$ & $\begin{array}{l}\text { hahahaha okay } \\
\text { wow im soooooo glad }\end{array}$ \\
\hline Emotion acronym & $\begin{array}{l}\text { lol } \\
\text { omg }\end{array}$ & $\begin{array}{l}\text { lol im not talking to you } \\
\text { omg for social we have to do this... }\end{array}$ \\
\hline Upper case & $\begin{array}{l}\text { THAT } \\
\text { WASH }\end{array}$ & $\begin{array}{l}\text { Not THAT nervous though. } \\
\text { u might have to actualy WASH that sweater }\end{array}$ \\
\hline Emotion punctuation & $\begin{array}{l}\cdots \cdots \cdots+\cdots \\
:)\end{array}$ & $\begin{array}{l}\text { so i was thinking........... } \\
\text { :) doo it hahah }\end{array}$ \\
\hline Errors & & \\
\hline Typographical error & $\begin{array}{l}\text { carzy } \\
\text { frwnch }\end{array}$ & $\begin{array}{l}\text { im too carzy } \\
\text { just finished studying } 4 \text { frwnch }\end{array}$ \\
\hline Misspelling & $\begin{array}{l}\text { embarrasing } \\
\text { progect }\end{array}$ & $\begin{array}{l}\text { how embarrasing.... } \\
\text { it's for like a psychology progect }\end{array}$ \\
\hline
\end{tabular}

instant messaging. Thus we collected authentic instant messages and spelling to examine relationships between new language use and gender and spelling ability.

\section{Method}

\section{Participants}

Participants were 40 adolescents (23 girls and 17 boys) ranging in age from 12 to 17 years, 10 months, with a mean age of 14 years, 5 months $(\mathrm{SD}=1$ year, 
5 months). The distribution of ages for boys and girls was roughly equivalent ( $M=14$ years, 6 months, $\mathrm{SD}=1$ year, 2 months, $M d n=14$ years, 6 months for girls and $M=14$ years, 3 months, $\mathrm{SD}=1$ year, 6 months, and $\mathrm{Mdn}=14$ years, 2 months for boys). The participants represented a convenience sample, that is, they were known by student researchers conducting the study as part of a senior level course in developmental psychology. Participants were average to above average in spelling ability, with a mean standardized score on the Wide Range Achievement Test (WRAT-3; Wilkinson, 1993) Spelling subtest of 110.7 (SD =13.1). An independent $t$-test comparing WRAT-3 Spelling subtest scores revealed no statistical significance between girls $(M=109.2, \quad \mathrm{SD}=12.2)$ and boys $(M=112.8$, $\mathrm{SD}=14.4)$.

\section{Apparatus and materials}

Each adolescent participant was required to have access to the Internet as well as an instant messaging program (e.g., MSN, AIM) on their computer. None of the instant messaging programs used by the participants had spell check or word completion options. In addition, the participants were required to be familiar with using and saving conversations through the instant messaging program and, if unsure, the researcher clarified instructions on how to save this type of information.

We used the WRAT-3 Spelling subtest to assess spelling ability. The test includes 40 words progressing in difficulty. To ensure that all participants received the same pronunciation, we created a digital recording of each of the words and context sentences. A member of the research team prepared the digital recording. Each word-context sentence-word recording was saved as a separate audio file to be delivered over the file sharing component of the instant messaging program.

\section{Procedure}

Written informed consent was obtained from a parent and oral or text (via instant messaging) assent was obtained from the adolescent participant prior to the start of the study. The student researcher asked the participant to save all computer-based instant message conversations for 1 week and, if the participant was unsure, the researcher provided instructions to save this type of information. Normal instant messaging conversations over the course of 1 week were then saved by the participant, and sent at the end of the week to the researcher.

Following the 1-week data collection period, the researcher administered the WRAT-3 Spelling subtest to the participant. The digitally recorded words were sent individually over the Internet through the same instant messaging program the participant had used to record his or her instant messages. The participant listened to each word-context sentence through an audio file, typed the spelling on a word pad document with spell check turned off, then sent the word list via email or instant messaging to the researcher.

From the collected instant messaging conversations, the researcher selected all messages that were written by the participant and discarded all messages written by others. The researcher then selected a random start point in the document and 
counted out a 100 word sample for analysis. Acronyms (e.g., lol) and word combinations (e.g., wanna) were counted as single "words." Punctuation and emoticons were not counted in the 100 words but were included in the analyses. Because the total number of analyzable data points per participant was greater than 100 in many cases, we report our analyses as words or instances of some form of text and not as percentages.

\section{Scoring}

Table 1 shows how we categorized new language use and provides examples for each category. We broadly categorized new language use into short cut, representing modifications of the spelling of specific words and phrases, and pragmatic device, representation changes that reflect pragmatic aspects of the message. We further classified short cuts into eight smaller categories and pragmatic devices into three smaller categories. We used NetLingo (http://www.netlingo.com) and Urban Dictionary (http://www.urbandictionary.com) to help identify new language use and etymology. We also scored apparent typographical errors and misspellings.

Within the short cuts category, we classified slang words commonly found on the Web as insider word (e.g., a hottie is a very attractive and desirable person; fugly is something or someone that is extremely ugly). We classified words commonly shortened by removing one or more phonemes or morphemes as abbreviation (e.g., according to Netlingo.com, prolly is a shortened form of probably) and contractions of multiple words into a single, phonetically spelled word (e.g., wanna for want to) as word combination. We classified common acronyms (e.g., lol for laughing out loud or bf for boyfriend) as acronym. We classified substitution of a word or part of a word with an alphabetic name (e.g., $u$ for you) or a number (e.g., 2morrow for tomorrow) as alphabetic/number words. We classified common phonetic spellings (e.g., wat for what) as phonetic new language words. We classified use of lower case where letters should be capitalized (e.g., as in the first letter of a proper noun) as lower case. We did not count the first word on a line (see example in conversation window in Fig. 1) as a lower case error even thought each line roughly corresponds to a sentence; thus, ignoring case may be underrepresented in our counts. We classified omission of an apostrophe (e.g., thats for that's) as contraction. We did not score other punctuation omissions as we could not determine whether a line break in sending an instant message was being used to represent punctuation.

Within the pragmatic devices category, we classified use of words to express emotion, such as representing laughter (e.g., hahaha) or repeating vowels to mirror pragmatic lengthening (e.g., whaaat to represent a drawn out expression of surprise) as emotion words. We classified use of acronyms to express emotion (e.g., lol) as emotion acronyms. We classified use of upper case to represent emotion (e.g., WHAT to represent surprise) as upper case and extraneous use of punctuation for emphasis [e.g., !!!!!) or as emoticons (e.g., 8-)] as emotion punctuation.

Finally, we classified common letter typing errors (e.g., knwo for know) as typographical error and apparently misspelled words (e.g., hungary for hungry) as 
misspelling. Neither of these categories is an example of new language so we classified these separately as Errors.

Some words received more than one classification; for example, from Table 1, the insider word, hottie, was in all uppercase letters and so was scored both an insider word and as upper case. Other examples of multiple classifications include $i m$, classified as lowercase and as a contraction error, and lol, classified both as a short cut acronym and as a pragmatic device emotion acronym. Approximately $3 \%$ of the words were scored as more than one category.

The conversations were initially scored by a group of researchers (the authors and others) to define the categories of new language. The conversations were then rescored by researchers naive to the initial discussions, using the categories of definitions. A $20 \%$ sample was then scored a third time by a new naive rater. Agreement on overall identification of a word a new language was 99\%. Cohen's kappa (Cohen, 1960) for inter-rater agreement on scoring into the different categories was $\kappa=0.97$, indicating excellent inter-rater reliability and ease of classifying instances of new language according to our classification scheme.

\section{Results}

As this was an exploratory study and we conducted a large number of analyses, we a priori guarded against family-wise error by applying Bonferoni corrections (dividing alpha $=0.05$ by the number of tests) to each set of statistical analyses conducted. Only results significant beyond the corrected alpha level are reported below.

\section{New language use}

Participants used an average of 31.8 instances of new language (SD = 14.1, range $=7-89$ ) in their instant messages. Table 2 shows the mean frequencies in new language use for the different categories of new language. The means among the different categories add up to greater than the overall total because a few words could be classified into two categories (e.g., im is classified as both lower case and a contraction error; WUT is classified as both phonetic and upper case).

Considering first the three groupings of categories, short cuts, pragmatic devices, and errors, we conducted a single factor repeated measures analysis of variance with the three general categories of short cuts, pragmatic devices, and errors as the repeated measures factor and participants as the random factor. We found a statistically significant difference among these three general categories, $F(2,78)=53.07$, $p<0.001$. Participants most often used short cuts in their instant messaging, followed by pragmatic devices to support their messages, followed by errors, Tukey's post hoc $\mathrm{HSD}=5.24, p<0.01$.

We also analyzed use of new language in each of the three general categories. We conducted a single factor repeated measures analysis of variance with the eight different shorts cuts categories as the repeated measures factor and participants as the random factor. We found a statistically significant difference among these three 
Table 2 Means, standard deviations, and ranges for the different types of new language use

\begin{tabular}{lrcl}
\hline Category & $M$ & SD & Range \\
\hline Short cuts & 21.7 & 9.3 & $4-43$ \\
Insider word & 0.5 & 0.8 & $0-3$ \\
Abbreviation & 2.9 & 2.7 & $0-11$ \\
Word combination & 0.8 & 0.9 & $0-3$ \\
Acronym & 2.5 & 2.0 & $0-8$ \\
Letter/number & 3.6 & 4.2 & $0-20$ \\
Phonetic & 1.2 & 1.8 & $0-7$ \\
Lower case & 7.0 & 3.7 & $0-14$ \\
Contraction & 3.6 & 2.6 & $0-10$ \\
Pragmatic devices & 9.7 & 10.3 & $1-60$ \\
Emotion word & 3.6 & 3.8 & $0-13$ \\
Emotion acronym & 1.4 & 1.5 & $0-5$ \\
Upper case & 2.9 & 8.3 & $0-50$ \\
Emotion punctuation & 1.8 & 1.8 & $0-7$ \\
Errors & 2.9 & 2.3 & $0-8$ \\
Typographical error & 1.8 & 1.9 & $0-7$ \\
Misspelling & 1.2 & 1.5 & $0-6$ \\
\hline
\end{tabular}

general categories, $F(7,273)=28.83, p<0.001$. Tukey HSD post hoc tests demonstrated that use of lower case (e.g., i just got home) was the most common short cut, HSD $=1.95, p<0.01$. Participants next most frequently used short cuts of abbreviations (e.g., doin), acronyms (e.g., bf), letter/number words (e.g., $u, r$ ), and omitting contraction punctuation (e.g., dont) in their instant messaging. The remaining short cuts of using insider words (e.g., hottie), word combinations (e.g., gonna) and phonetic representations (e.g., wuz) —all commonly cited in the news media as new language-were least commonly observed.

Participants used pragmatic devices less than half as often as they used short cuts. We conducted a single factor repeated measures analysis of variance with the four different categories of pragmatic devices as the repeated measures factor and participants as the random factor. This analysis was not statistically significant. Participants were extremely variable in their use of pragmatic devices, ranging from five participants who used only one pragmatic device each to one participant for whom we counted 60 cases of use of pragmatic devices in his instant messaging, including frequent use of upper case letters (e.g., WHAT), pragmatic lengthening (e.g., jeasuuuus), and emotion acronyms e.g., wtf).

Somewhat unexpectedly, especially given the number of emoticons available with instant messaging programs such as MSN, the participants used few emoticons in their instant messaging conversations; less than half of the cases of emotion punctuation use consisted of emoticons. However, unless a participant had assigned function keys or specific key combinations to represent different emoticons, adding emoticons to an instant message is time consuming and involves making mouse movements to select from various menus, requiring the user to remove a hand from the keyboard and look at the monitor to make selections. 
We also found few typographical errors and misspellings in our corpus. A paired samples $t$-test revealed no statistically significant differences between misspellings and typographical errors. Misspellings were generally phonetic misspellings of words that are not likely of high enough frequency to merit a short cut of their own (e.g., actualy, awsome). Typographical errors included common right-left hand errors, such a knwo (knwo is such a common typographical error that some word processing programs will automatically correct for it), letter reversals (e.g., carzy for crazy), and extra letters that are adjacent on the keyboard (e.g. whatds).

We found many individual differences in use of new language. For example, one participant expressed shock with pragmatic lengthening (WHAT), another used pragmatic lengthening (whaaaat), and another added extra punctuation (what!!!!!). Similarly, one participant finished a conversation with word combination (gotta go), another used an acronym $(g 2 g)$, and another used a number word ( $g o t 2 g o$ ). These individual differences led to few correlations between different types of new language use, namely between abbreviations and use of word combinations, $r(38)=0.61, p<0.001$, and between typographical errors and use of upper case to express emotion, $r(38)=0.51, p<0.005$. On the other hand, these correlations make intuitive sense: both abbreviations (e.g., em for them or cause for because) and word combinations (e.g., gonna for going to or kinda for kind of) shorten common words and speed up typing. Use of upper case requires holding down the shift key or setting and unsetting the "Caps Lock" key and can easily lead to typographical errors.

Effects of gender, age, and spelling on new language use

Because age and spelling ability as measured by standardized scores on the WRAT Spelling subtest are continuous variables, we conducted multiple regression analyses, as opposed to analysis of variance, to examine the effects of gender, age, and spelling ability on new language use. Because we were interested in potential interactions among these independent variable, we also used centered variables to allow us to include interaction effects. Centering variables controls for issues with multicolinearity between the variable and their interactions and allows for easier interpretation of the regression coefficients (Aiken \& West, 1991). As well, because we had no a priori expectations about how all the variables might or might not fit in the model, we conducted stepwise analyses. Identical to analysis of variance, the weightings and statistical significance of the independent variables and their interactions in the stepwise multiple regressions alerted us to the importance of these variables. We then decomposed the statistically significant interaction effects using correlational analyses.

We conducted a total of 15 stepwise multiple regressions, considering total new language use and each category of new language use as the dependent variables. We obtained statistically significant results for total new language use, use of abbreviations, and misspellings.

Considering first total new language use, we found a statistically significant effect of gender and an interaction between gender and spelling ability, $F(2,37)=7.05$, 
$p<0.005$, adjusted $R^{2}=0.24, \beta=-0.41$ for gender and $\beta=-0.32$ for gender by spelling ability. Girls used more new language $(M=35.7, \mathrm{SD}=14.6$, range $=$ $20-89)$ in their instant messaging than did boys, $(M=26.4, \mathrm{SD}=11.7$, range $=$ 7-40). Decomposing the interaction, we found a statistically significant correlation for boys between WRAT and new language use in instant messaging, $r(15)=-0.54$, $p<0.05$, but not for girls, indicating that boys who were relatively poorer spellers used more new language than did boys who were relatively better spellers.

For use of abbreviations (e.g., feelin), we found an interaction between gender and spelling ability, $F(1,38)=30.34, p<0.001$, adjusted $R^{2}=0.43, \beta=-0.67$. Decomposing this interaction, we found a significant positive correlation between WRAT and use of abbreviations in instant messages for girls, $r(21)=0.51$, $p<0.05$, and a significant negative correlation for boys, $r(15)=-0.77, p<0.001$. This indicates that girls who were relatively better spellers used more abbreviations in their instant messaging than did girls who were relatively poorer spellers but boys who were relatively better spellers used fewer abbreviations than did boys who were relatively poorer spellers.

Finally, for misspellings (e.g., definitly), we found a significant effect of spelling ability, $F(1,38)=28.38, p<0.001$, adjusted $R^{2}=0.41$. Overall, relatively better spellers made fewer spelling errors than did relatively poorer spellers, $\beta=-0.65$.

\section{Discussion}

Adolescents' instant messaging contains a wide variety of types of new language characters and words. We identified 14 types of new language that we could group into three broad classes representing short cuts to speed communication, use of pragmatic devices to substitute for nonreferential communication in face-to-face exchanges, and errors. Girls used more new language overall than did boys and we found no effects of age on any of our measures of new language use. Contrary to what the media and parents might argue, spelling ability was not highly correlated with new language use in instant messaging. With two exceptions, general spelling ability was only related to true spelling errors and not to all types of new language use in instant messaging.

Adolescents predominantly use instant messaging to make and change plans, chat in small groups, and discuss homework-usually while engaging in other activities at the same time (Grinter et al., 2006; Lenhart et al., 2007; Lenhart et al., 2005; Lenhart et al., 2001). Any mechanism that speeds up necessarily time-consuming typing leads to faster and more efficient instant messaging. Driscoll (2002) analyzed transcripts from adults' use of chat while interacting in online gaming and identified similar use of short cuts. Driscoll argued that the use of short cuts in the game chat logs she analyzed functioned to allow game players to communicate quickly. It is much quicker to type an abbreviation than an entire word (e.g., em for them) and an acronym than an entire phrase (e.g., gtg for got to go). Given that instant messages are brief communications, it is not surprising that we found that most new language use was in the form of linguistic and paralinguistic short cuts. 
It is also efficient to dispense with capitalization and punctuation, so long as the message is clear. Pragmatic devices, such as emoticons, use of capitals for emphasis, and emotion words/acronyms, help users of instant messaging clarify meaning. In face to face conversation, emotion and attitude are expressed in facial expressions, such as smiling or frowning (Jakobson, 1960). In text, emotion must be made explicit; Stevenson \& Shortis, (n.d.) argued that emoticons, and other paralinguistic pragmatic devices, such as use of capitalization for "shouting," are unique adaptations for expressing emotion in text without providing lengthy written explanations. We found a number of cues to emotion, ranging from use of emotion words (e.g., hahaha) and acronyms (e.g., lol) to excessive use of punctuation (e.g., !!!!) and upper case (e.g., WHAT) to express emotion.

Typing quickly can lead to errors. Some errors have become so common that they may be becoming new language words themselves, such as the typographical error spelling for knwo, which now exists as an entry in the Urban Dictionary (http:// www.urbandictionary.com). Surprisingly, we found few typographical errors or misspellings in our study, but misspellings were predicted by spelling ability. On the other hand, abbreviations, acronyms, letter or number words, and phonetic spellings are all short cuts that minimize typographical errors and misspellings in the first place.

Our development of a taxonomy of short cuts, pragmatic devices, and errors has several important uses, including comparing new language use across different media, the acquisition of new language by children, and documenting the evolution of new language as we increasingly rely on text-based forms of communication. Investigating use of new language across different media, ranging from different forms of electronic communication programs, such as instant messaging, chat, and e-mail, to written work in school is important for understanding how people adapt language to serve different functions. As well, to dispel concerns that new language use in instant messaging is ruining children and adolescent's ability to write essays and formal communications using conventional language (e.g., Lee, 2002), future research can examine intrusions (or lack thereof) of new language into classroom writing. Instead of becoming detrimental, instant messaging may actually encourage school writing; Spatafora (2008) argued that we may wish to use instant messaging for educational purposes and motivate school writing while, at the same time, building in instruction in conventional forms of writing.

If new language in instant messaging is truly a new form of written communication, then our taxonomy is important for documenting the evolution and acquisition of this form of communication over time and over contexts, particularly when combined with ethnographic research designs as advocated by Jacobs (2004).

Although we did not find any age effects in use of new language, we did have a relatively restricted range of adolescents. Future studies need to consider a broader range of youth. Most interesting would be a longitudinal study of children as they begin to use instant messaging.

The literature is equivocal in terms of gender differences in instant messaging and the use of other forms of electronic communication, with Lee (2003) finding that female college students use more emoticons in instant messaging than do males and Huffaker and Calvert (2005) finding that adolescent males use more emoticons 
in blogging than do females. By contrast, we found that, although girls used new language more often in their instant messaging than did boys, there were no effects of gender on uses of pragmatic devices as well as no consistent gender differences in any other categories of new language.

Contrary to the dire predictions in the press and by parents and teachers (e.g., Lee, 2002; http://www.oxfordlearning.com/letstalk/texting-vs-writing-the-problemwith-instant-messag/), focusing on how instant messaging is ruining spelling and language development, we found few relationships between new language use and spelling ability. Although we can not make causal conclusions and additional research is needed, we are optimistic that spelling ability is not adversely affected by instant messaging.

We offer two arguments for our optimism: first, other than the errors category, consisting of typos and misspellings, we found no relationships between spelling ability and use of new language. We did find a few interactions between spelling ability and gender. Foe example, we found that boys who were less able spellers used more new language overall and also used more abbreviations than did boys who were more able spellers. However, we did not find a consistent relationship between spelling ability and new language use, in that girls who were better spellers used more abbreviations, and we did not find a relationship between spelling ability and other short cuts to complete spelling, such as phonetic spelling or letter/number word substitutions. Younger and poorer spellers tend to use phonetic and letter name spelling strategies (Bernstein, 2008; Bourassa \& Treiman, 2003; Treiman, 1993, 1994, 1997) in their conventional writing.

We also did not find any apparent misspellings in new language words. No participant combining modal auxiliaries misspelled the auxiliary verb (e.g., shoulda was never spelled phonetically as shuda) and no participant misspelled an abbreviation (e.g., prolly was never spelled proly). The adolescents in our study were learning correct new language spellings_-and without conventional instruction!

This is not to say that spelling is not important for new language use in instant messaging. Future studies, investigating the acquisition of new language in instant messaging should examine how children and adolescents are learning this new language. Given our ability to collect the entire instant message history, studying new language acquisition in instant messaging and in other forms of electronic communication has important implications for theories of multiple language acquisition and spelling, especially in the absence of direct instruction. This research also has practical applications for designing better instant messaging and cell phone text messaging word completion programs.

There is much controversy surrounding children's and adolescents' use of instant messaging and other forms of electronic communication. We prefer to view electronic communication as both a new, complementary language to conventional written language and a natural experiment in the development of written communication. The taxonomy we have developed in this study provides an important tool for investigating new language. Our findings regarding spelling ability and new language use should allay the fears of those who are concerned that new language will have detrimental effects on conventional written language. 


\section{References}

Aiken, L., \& West, S. (1991). Multiple regression: Testing and interpreting interactions. Newbury Park, CA: Sage.

Bernstein, S. E. (2008). Phonology, decoding, and lexical compensation in vowel spelling errors made by children with dyslexia. Reading and Writing: An Interdisciplinary Journal. Advance online publication. Retrieved April 22, 2008 doi:10.1007/s11145-008-9116-z.

Bourassa, D., \& Treiman, R. (2003). Spelling in children with dyslexia: Analyses from the TreimanBourassa early spelling test. Scientific Studies of Reading, 7, 309-333.

Cohen, J. (1960). A coefficient of agreement for nominal scales. Educational and Psychological Measurement, 20, 37-46.

Crystal, D. (2006). Language and the internet (2nd ed.). Cambridge: Cambridge University Press.

Cummins, J. (1979). Linguistic interdependence and the educational development of bilingual children. Review of Educational Research, 49, 222-251.

Davis, B. H., \& Brewer, J. P. (1997). Electronic discourse: Linguistic individuals in virtual space. Albany, NY: State University of New York Press.

Driscoll, D. (2002). The Ubercool morphology of internet gamers: A linguistic analysis. Undergraduate Research Journal for the Human Sciences, 1. Retrieved from http://www.kon.org/urc/driscoll.html.

Figueredo, L. (2006). Using the known to chart the unknown: A review of first-language influence on the development of English-as-a-second-language spelling skill. Reading and Writing, 19, 873-905.

Grinter, R. E., Palen, L., \& Eldridge, M. (2006). Chatting with teenagers: Considering the place of chat technologies in teen life. ACM Transactions on Computer-Human Interaction, 13, 423-447.

Herring, S. C. (1999). Interactional coherence in CMC. Journal of Computer-Mediated Communication, 4(4). Retrieved from http://jcmc.indiana.edu/vol4/issue4/herring.html.

Herring, S. C. (2003). Computer-mediated communication on the internet. In S. B. Barnes (Ed.), Computer-mediated communication: Human to human communication across the internet (pp. 109168). Boston: Pearson Education.

Huffaker, D. A., \& Calvert, S. L. (2005). Gender, identity, and language use in teenage blogs. Journal of Computer-Mediated Communication, 10 (2), article 1. Retrieved from http://jcmc.indiana.edu/ vol10/issue2/huffaker.html.

Jacobs, G. E. (2004). Complicating contexts: Issues of methodology in researching the language and literacies of instant messaging. Reading Research Quarterly, 39, 394-406.

Jakobson, R. (1960). Linguistics and poetics. In T. A. Sebeok (Ed.), Style in language (pp. 350-377). Cambridge, MA: MIT Press.

Jansen, E. (2003). Netlingo: The internet dictionary. Ojai, CA: Netlingo, Inc.

Kang, H.-S., \& Yang, H. (2006). The visual characteristics of avatars in computer-mediated communication: Comparison of internet relay chat and instant messenger as of 2003. International Journal of Human-Computer Studies, 64, 1173-1183.

Kruger, J., Epley, N., Parker, J., \& Ng, Z. (2005). Egocentrism over email: Can we communicate as well as we think? Journal of Personality and Social Psychology, 89, 925-936.

Lee, C. (2003). How does instant messaging affect interaction between the genders? Unpublished manuscript, Stanford University.

Lee, J. (2002). I think, therefore IM. New York Times, p.G.1.

Lenhart, A., Madden, M., \& Hitlin, P. (2005). Teens and technology: Youth are leading the transition to a fully wired and mobile nation. Washington, DC: Pew Internet \& American Life Project. Retrieved from http://www.pewinternet.org/pdfs/PIP_Teens_Tech_July2005web.pdf.

Lenhart, A., Madden, M., Macgill, A. R., \& Smith, A. (2007). Teens and social media. Washington, DC: Pew Internet and American Life Project. Retrieved from http://www.pewinternet.org/pdfs/PIP_ Teens_Report.pdf.

Lenhart, A., Rainie, L., \& Lewis, O. (2001). Teenage life online: The rise of the instant-message generation and the internets impact on friendships and family relationships. Pew Internet and American Life Project. Retrieved from http://www.pewinternet.org/reports/pdfs/PIP_Teens_ Report.pdf.

Lewis, C., \& Fabos, B. (2005). Instant messaging, literacies, and social identities. Reading Research Quarterly, 40, 470-501.

Merchant, G. (2001). Teenagers in cyberspace: An investigation of language use and language change in internet chatrooms. Journal of Research in Reading, 24, 293-306. 
Shoeman, E., \& Shoeman, J. (2007). Text messaging survival guide. Victoria, BC: Trafford Publishing.

Sparks, R. L., Patton, J., Ganschow, L., Humbach, N., \& Javorsky, J. (2008). Early first-language reading and spelling skills predict later second-language reading and spelling skills. Journal of Educational Psychology, 100, 162-174.

Spatafora, J. N. (2008). IM learning 2 write? A study on how instant messaging shapes student writing. Unpublished master's thesis, Queens University, Kingston, Ontario, Canada.

Spears, G., Seydegart, K., \& Zulinov, P. (2005). Young Canadians in a wired world, phase II: Student survey. Ottawa: Media Awareness Network. Retrieved from http://www.media-awareness.ca/ english/research/YCWW/phaseII/upload/YCWWII_Student_Survey.pdf.

Sternberg, B. J., Kaplan, K. A., \& Borck, J. E. (2007). Enhancing adolescent literacy achievement through integration of technology in the classroom. Reading Research Quarterly, 42, 416-420.

Stevenson, J., \& Shortis, T. (n.d.) The language of internet relay chat. Retrieved April 22, 2008, from http://www.demo.inty.net/Units/Internet\%20Relay\%20Chat.htm.

Tagliamonte, S. A., \& Denis, D. (2006). LOL for real! Instant messaging in Toronto teens. Toronto, Ontario, Canada: Linguistic Association of Canada and the United States (LACUS).

Treiman, R. (1993). Beginning to spell: A study of first-grade children. New York: Oxford University Press.

Treiman, R. (1994). Use of consonant letter names in beginning spelling. Developmental Psychology, 30, 567-580.

Treiman, R. (1997). Spelling in normal children and dyslexics. In B. Blachman (Ed.), Foundations of reading acquisition and dyslexia: Implications for early intervention (pp. 191-218). Hillsdale, NJ: Erlbaum.

Werry, C. C. (1996). Linguistic and interactional features of internet relay chat. Philadelphia, PA: John Benjamins Publishing.

Wilkinson, G. S. (1993). Wide range achievement test-3. Wilmington, DE: Jastak. 